\title{
Information Technology: A Study Of Accountants' Skills And Knowledge Levels
}

J. Harrison McCraw, (E-mail: jmccraw@westga.edu), State University of West Georgia John R. O’Malley, (E-mail: omalley@email.uncc.edu), University of North Carolina- Charlotte Bruce M. Bird, (E-mail: bbird@westga.edu), State University of West Georgia

Lance A. Matheson, (E-mail: lance@ vt.edu), Virginia Tech

\begin{abstract}
This article examines the results of a survey mailed to 940 accounting professionals in which they identify the categories of IT skills and knowledge that are required to perform their job. Using cluster analysis, this article next examines whether Band to what extentB relationships exist between different categories of IT skills and knowledge. Survey results are then presented regarding methods by which accounting professionals acquire needed job-related IT skills and knowledge.
\end{abstract}

\subsection{Introduction}

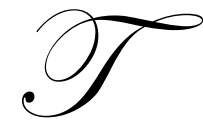

oday most accountants embrace a number of Information Technology (IT) tools and techniques. Specifically, IT has a profound effect upon 1) the organizational responsibilities of accountants and 2) the professional services they offer. This article examines the results of a survey mailed to accounting practitioners. This survey focuses on job-related IT skills and knowledge required of accountants.

\subsection{The Survey}

The authors developed a survey instrument and mailed it to 940 accounting practitioners belonging to a large IMA chapter in the Southeastern part of the United States. We received a total of 216 survey responses. Members of the survey group include CPAs, CMAs, joint CPA/CMAs, accountants holding other certifications, and accountants possessing no certification.

Members of the survey group practice in the public, for-profit, and not-for-profit areas. Their average age is 41.6 years. They have a mean of 15.3 years of professional experience. Members of the survey group are $60 \%$ male and $40 \%$ female; $98 \%$ have a bachelor $=\mathrm{s}$ degree and $47 \%$ have a master $=\mathrm{s}$ degree.

The survey participants answered a series of questions regarding the IT skills and knowledge required for their jobs, the ways in which they acquire IT skills and knowledge, and the effects of IT upon their work environments.

\subsection{IT Categories of Skills And Knowledge}

From a list of 11 IT skills and knowledge categories, survey participants identified those categories that are required for their job. A total of 209 of the 216 respondents answered this section. Their responses, ranked by response frequencies, are shown in Table 1.

Readers with comments or questions are encouraged to contact the authors via email. 
Table 1 Job-Related IT Skills and Knowledge Required of Employee

\begin{tabular}{|l|l|c|c|c|}
\hline & \multicolumn{1}{|c|}{ Skills and Knowledge } & Yes & No & Proportion Yes \\
\hline 1 & Basic Application Programs & 207 & 2 & 0.99 \\
\hline 2 & Basic Computer Tasks & 204 & 5 & 0.98 \\
\hline 3 & Basic Hardware & 190 & 19 & 0.91 \\
\hline 4 & Computer Operating Systems & 187 & 22 & 0.89 \\
\hline 5 & Client/Server Environment & 124 & 85 & 0.59 \\
\hline 6 & Accounting Software & 120 & 89 & 0.57 \\
\hline 7 & Database Software & 109 & 100 & 0.52 \\
\hline 8 & Network Operating Systems & 86 & 123 & 0.41 \\
\hline 9 & Data Telecommunications & 84 & 125 & 0.40 \\
\hline 10 & ERP Software & 75 & 134 & 0.36 \\
\hline 11 & Mainframe/Terminal Environment & 68 & 141 & 0.33 \\
\hline
\end{tabular}

Over $89 \%$ of the respondents indicated that the first four categories listed in Table 1 of IT knowledge are required for their job. Of the 209 respondents surveyed, 207 indicated that basic application program knowledge is required. This includes familiarity with popular word processing programs such as Word or WordPerfect; spreadsheet programs such as Lotus 1-2-3 and Excel; and e-mail. In addition, almost all respondents reported that knowledge of basic computer tasks, such as working with folders and managing computer files, is necessary. Finally, accountants are generally required to know about basic computer hardware and computer operating systems.

Over $52 \%$ of the accounting professionals surveyed indicated that the fifth, sixth, and seventh categories mentioned above are also necessary for their job. These include familiarity with the client/server environment, accounting software packages, and database software. Finally, $41 \%$ or fewer of the respondents indicated that each of the last four categories were important for their job.

In addition, the accountants surveyed believe that knowledge of client/server computing (59\%) is more important than that of the main frame/terminal computing environment (33\%). This matches industry movement from the mainframe environment to the client/server environment.

\subsection{Cluster Analysis}

The results in Table 1 suggest that relationships exist between different categories of IT skills and knowledge. In order to examine to what extent such relationships exist, the authors performed cluster analysis on the IT knowledge categories. Cluster analysis categorizes individual responses into groups that are based upon similar traits. We determined that a 4-cluster solution fits the data. The results of the cluster analysis are shown in Table 2.

Table 2 Classification of IT Skills and Knowledge Clusters

\begin{tabular}{|l|l|}
\hline Cluster & \multicolumn{1}{|c|}{ IT Skills and Knowledge } \\
\hline 1 & $\begin{array}{l}\text { Basic Computer Tasks such as working with folders and file management } \\
\text { Basic Application Programs such as spreadsheets, e-mail, virus software } \\
\text { Basic Computer Hardware such as printers, personal computers, multifunction devices } \\
\text { Computer Operating Systems such as Windows 98/ 2000, Mainframe operating systems }\end{array}$ \\
\hline 2 & $\begin{array}{l}\text { Client/Server Environment } \\
\text { Mainframe/Terminal Environment } \\
\text { Data Telecommunications } \\
\text { Network Operating Systems such as NT, Unix, Novell Netware }\end{array}$ \\
\hline 3 & Accounting Software Package such as Peachtree or QuickBooks \\
\hline 4 & $\begin{array}{l}\text { ERP Software such as PeopleSoft, SAP, Oracle } \\
\text { Database Software such as Access, Oracle 8, SQL Server }\end{array}$ \\
\hline
\end{tabular}


The $1^{\text {st }}$ cluster consists of relatively basic IT skills and knowledge. This cluster consists of the first four categories found in Table 1; basic computer tasks, basic application programs, basic hardware, and computer operating systems. The $2^{\text {nd }}$ cluster consists of a related group of four ITs used for communications between and among computers. This cluster consists of the following Table 1 categories: client/server environment, mainframe/terminal environment, data telecommunications, and network operating systems.

The $3^{\text {rd }}$ cluster consists solely of the specialized accounting software category and included software packages such as Peachtree Accounting or QuickBooks. Concerning the $3^{\text {rd }}$ cluster of IT skills and knowledge, slightly more than $57 \%$ of respondents indicated a need to know a specialized accounting software package such as Peachtree Accounting or QuickBooks. It is unclear whether such respondents interpreted the survey question to focus solely upon their use of Peachtree Accounting or QuickBooks, or whether they interpreted the survey question to focus upon their use of Peachtree Accounting, QuickBooks, or other specialized accounting software packages. One possibility is that the accountants surveyed are more inclined to use Peachtree Accounting or QuickBooks at work. A second possibility is that the respondents typically work for organizations that are more inclined to use customized or proprietary accounting software packages.

The $4^{\text {th }}$ cluster, consisting of the ERP software and database software categories found in Table 1, involves related technologies. ERP software is usually highly dependent upon database software. Both also tend to be relatively complex technologies.

\subsection{Implications Of IT Skills And Knowledge Levels}

Based on the survey responses and the analysis presented in Tables 1 and 2, virtually all employers require their accountants to have basic IT skills and knowledge. Due to survey limitations, it is not known if such basic skills and knowledge are an employment prerequisite or are acquired on the job. While most employers expect their employees to be, at a minimum, Acomputer literate $@$, some of employers may provide their new hires with a certain period of time within which to acquire needed IT skills and knowledge.

The more complex IT skills and knowledge found in the $2^{\text {nd }}$ and $4^{\text {th }}$ clusters are less likely to be required by employers than those in the $1^{\text {st }}$ cluster. Respondents indicate that they regularly acquire new IT skills and knowledge. Alternatively, the lower response rate in the $2^{\text {nd }}$ and $4^{\text {th }}$ clusters may reflect that these IT skills and knowledge are not required of employees for completing their current job assignments.

Moreover, in difficult economic times, some firms may reduce their accounting staff to the point where the employees who remain do not have enough time to learn and implement the more complex technologies mentioned above. While evidence exists that organizations are adopting more complex information technologies, many of these organizations may be reluctant to invest in the IT intellectual capital of their accounting employees. Survey participants averaged only 17.5 hours of Aformalized@ IT training per year. The accountants surveyed indicated their need for additional Aformalized@ IT training.

\subsection{Acquiring IT Skills And Knowledge}

Another part of our survey examined how accountants are acquiring new IT skills and knowledge from among the nine methods listed in Table 3.

The respondents ranked their top 3 methods for acquiring IT skills and knowledge. For the most important method, respondents selected the number A $1 @$; for the second, the number $\mathrm{A} 2 \mathrm{Q}$; and for the third, $\mathrm{A} 3 \mathrm{C}$. Not all respondents correctly filled out this portion of the survey. As a result, a total of 177 usable responses remained. Table 3 lists the number of ranked responses for the nine methods of learning IT.

In order to gain insight into how accountants perceived the nine different IT learning methods, a Weighted Score is calculated for each of the methods. The Weighted Score is calculated by multiplying the number of A $1 @$ responses by 
3 , the number of $A 2 @$ responses by 2 and the number of $A 3 @$ responses by 1 . The total is then divided by the total number of responses (177). The higher the Weighted Score for a method the more important the method is to accountants. These scores are shown in the last column of Table 3.

Table 3 Frequencies of IT Training (Learning) Options

\begin{tabular}{|l|l|c|c|c|c|c|}
\hline & & \multicolumn{4}{|c|}{$\begin{array}{c}\text { Summed Responses Choices listed as 1 } \\
\text { most important, 2 as second most } \\
\text { important, 3 as third most important }\end{array}$} & Not Selected \\
\hline & & $\mathbf{1}$ & $\mathbf{2}$ & $\mathbf{3}$ & \multicolumn{2}{c|}{ Weighted Score } \\
\hline 1 & College Courses & 6 & 11 & 13 & 147 & 0.30 \\
\hline 2 & Professional Organizational Training & 22 & 11 & 11 & 133 & 0.56 \\
\hline 3 & Learn on the Job B Instructor based & 12 & 18 & 15 & 132 & 0.49 \\
\hline 4 & Vendor Training & 11 & 12 & 15 & 139 & 0.41 \\
\hline 5 & Learn on the Job B Computer, video, etc. & 10 & 24 & 26 & 117 & 0.59 \\
\hline 6 & In-House Training & 16 & 37 & 15 & 109 & 0.77 \\
\hline 7 & Learn on the Job B AHands-on@ & 92 & 39 & 21 & 25 & 2.12 \\
\hline 8 & Learn at Home & 10 & 19 & 31 & 117 & 0.56 \\
\hline 9 & Other & 1 & 6 & 7 & 163 & 0.12 \\
\hline
\end{tabular}

By a wide margin, respondents appear to be using Method 7 (ALearn on the Job B Hands On@) as their primary method of learning IT. In addition, the second and third most important methods of acquiring IT --Methods 6 and 5, respectively-- involve types of on-the-job training.

\subsection{Conclusion}

From our study, it appears that basic IT skills and knowledge are required of most of the accountants surveyed. This includes knowledge and use of basic application programs, basic computer tasks, basic hardware, and computer operating systems. In addition, a majority of the accountants surveyed indicated the need for IT skills and knowledge relating to the client/server environment, accounting software, and database software. We also determined that accountants IT skills and knowledge tended to group into 4 distinct clusters of technical competency.

We next examined the methods in which accountants acquire IT skills and knowledge. The accountants surveyed indicated that they primarily acquire new IT skills and knowledge through Ahands on@ on-the-job-training.

In addition, the accountants surveyed in our study indicated that while the IT knowledge required for their jobs is increasing, they receive less than 18 hours of formalized IT training each year. This suggests that additional formal IT training may be needed. Arguably, for such training to be effective, it should be timely, cost effective, conveniently located, and held on an ongoing basis. 